\title{
Shared-Use Mining Infrastructure: Why it Matters, and How to Achieve it
}

Glen Ireland and Paul Collier*

\section{Abstract}

This article considers the cases for and against 'open access' regulation of rail and port logistics infrastructure used by 'bulk' mining operations, arguing that host governments should proactively impose and then enforce such regulation in almost all cases for the reasons that follow. The logistics infrastructure needed for this type of mining activity is of critical importance. The costs and potential inefficiencies involved in duplicating such infrastructure confer a significant competitive advantage on its owner in the absence of effective access regulation. In particular, where a first-mover develops an 'integrated' project incorporating a mine and associated infrastructure, a failure to impose access regulation discourages thirdparty investment in mineral exploration and development in the region serviced by the infrastructure, due to the risk of hold up by the first mover. An unregulated first mover can also use its infrastructure advantage to capture the state's share of resource rents from the mineral endowment of the region. Open access regulation further benefits host countries by enabling broad-based economic development through the shared-use of mining infrastructure with other sectors (e.g., agribusiness). The article highlights contrasting experience with access regulation in Australia: the Pilbara iron ore region has seen protracted disputes involving mining firms and policymakers and very few examples of third party access, while in the coal region of central Queensland an extensive multi-user, multi-purpose railway network operates independently of mining firms. The authors urge governments in subSaharan Africa (in particular) not to underestimate the internal capacity and other challenges associated with developing and enforcing open access regulation of mining infrastructure in a manner that protects their national interests.

Key words: Infrastructure, mining, open access regulation, sub-Saharan Africa

\footnotetext{
* Respectively, Co-Director of the Centre for the Study of African Economies and Professor of Economics and Public Policy at the Blavatnik School of Government, University of Oxford; and Honorary Associate of the Centre for Energy, Mineral and Petroleum Law and Policy, University of Dundee and a Founding Partner of InfraShare Partners Limited.
} 
The key to economic development and prosperity for many countries in sub-Saharan Africa lies, at least initially, in the effective exploitation of their natural resource wealth. Historically underexplored and underdeveloped (Collier, 2010), the region's sub-soil potential has in recent years been the subject of greater attention and more intense competition as China and other emerging industrial economies seek direct access to bauxite, coal, iron ore, manganese, potash and other 'bulk' commodities. A lack of available rail, port and other critical infrastructure has long represented a major obstacle to developing many of Africa's worldclass mineral deposits. Whilst recent declines in commodity prices have reduced the nearterm prospects for investment in major 'greenfield' mining projects, there seems little doubt that sub-Saharan Africa will eventually take its place as one of the world's leading suppliers of bulk minerals. In the current subdued investment climate, African governments have an invaluable opportunity to plan the future development of their natural resources and, in particular, to consider how anticipated investments in mining-related infrastructure can best serve their national interests.

Many large, previously-discovered, but yet-to-be-developed bulk mineral deposits are located in remote, poorly-explored and highly-prospective regions, particularly those found in subSaharan Africa. Mining of these deposits requires major investment in rail, port, power and other infrastructure, the cost of which is often multiples that required to construct the mineral extraction and processing facilities. The infrastructure, when constructed by a 'first mover' mining firm, holds significant potential in terms of other economic activity that might benefit from it, including further mineral exploitation and/or the development of other industries or services. Whether or not such potential is ever realised will depend, to a large degree, on the arrangements in place between the host government and first mover concerning the financing, construction, ownership, operation and use of the infrastructure.

It has been typical in many developing countries (and is not unknown in developed countries such as Australia and Canada) for large mines to be developed as 'integrated' projects in which both mining and infrastructure facilities are owned and/or operated under the exclusive, largely unrestricted control of a first mover. We consider the implications of the integrated mining model for host countries, and examine the case for imposing 'open access' regulation on bulk mining infrastructure. We argue that the large fixed costs and potential inefficiencies involved in duplicating critical logistics infrastructure confers a significant competitive advantage on its owner in the absence of effective access regulation. Further, we show how 
a failure to impose open access regulation on a first mover's infrastructure discourages thirdparty investment in bulk mineral exploration and development in the region serviced by such infrastructure due to the risk of hold up by the first mover. We also illustrate how an unregulated first mover can use its competitive position to capture the host government's share of resource rents from the same region. In addition to facilitating upstream investment and protecting the state's share of resource rents, we argue that open access regulation enables broad-based economic development through shared-use of the infrastructure among mining firms and other sectors (e.g., agribusiness, freight transportation and passenger services). Based on the foregoing, we conclude that host governments should proactively impose and then take steps to enforce effective open access regulation on mining infrastructure in almost all cases.

The article begins with a general description of bulk mining, focusing on the important role played by 'pit-to-port' logistics infrastructure and the various approaches to its ownership, operation and regulation seen globally. We then describe the manner in which mining firms engaged in exploring for and developing bulk mineral deposits evaluate new potential targets, and how 'infrastructure risk' influences their investment decisions. We go on to discuss the case for regulating open access to mining infrastructure, drawing upon relevant economic theory as well as recent literature on the challenges and opportunities associated with shareduse mining infrastructure. We also consider (and reject) various arguments made against open access regulation of mining infrastructure, including those seen recently in public submissions made by several major mining firms in connection with a review of competition policy in Australia (including that country's 'National Access Regime'). We review experience in Australia's iron ore-rich Pilbara region, where for decades open access regulation has given rise to highly contentious and protracted disputes involving various mining firms and government agencies. Drawing on wider experience in Australia and elsewhere, we outline key considerations for host governments seeking to introduce open access regulation of mining infrastructure. Finally, we urge host governments including, in particular, those in subSaharan Africa not to underestimate the challenges associated with developing and enforcing effective and workable open access regulation in relation to mining infrastructure, and welcome plans to develop good practice in this area.

\section{Bulk Mining, and the Importance of Logistics Infrastructure}

Major deposits of bulk commodities, which have a relatively low value-to-weight ratio, are typically exploited in large-scale operations involving the extraction and transfer of vast quantities of material. The realisation of such projects generally involves the following 
discrete phases: exploration, development, construction and operation. In the exploration phase, a mining firm seeks to identify a large, high-grade, near-surface and well-situated mineral deposit. The main geological formations in which such deposits exist are, in general, widely understood within the global mining industry. Exploration activity seeks, however, to ascertain in detail the characteristics of individual deposits, and to rank or prioritise them in terms of economic potential. The cost of the exploration phase varies considerably, depending upon the amount of drilling undertaken, the remoteness of the location and other factors. Most bulk mineral projects are abandoned at the end of this phase and, accordingly, exploration investment involves considerable commercial risks.

In the development phase, a mining firm seeks to determine whether exploitation of an individual deposit, or perhaps a group of related deposits, would be economically viable. The development phase includes additional site work and preparation of a detailed feasibility study, the cost of which can often exceed US\$100 million. The duration of the development phase can be 4 to $20+$ years, depending on factors such as commodity prices, global financial and construction markets, the host country's election cycle and the mining firm's financial strength - all of which need to align favourably. In most cases, the mining firm determines at the end of the development phase to terminate the project, sell it to a third party or hold it in 'inventory' pending more favourable conditions. In a small number of cases, the firm decides to proceed with construction of a mining project.

The construction phase involves readying the mineral deposit for exploitation, constructing processing and other mine-site facilities, and building any required logistics infrastructure such as a railway and/or port. Costs of construction vary considerably depending upon on the size of the mine, its location relative to the sea and other factors, but typically run to many billions of U.S. dollars. It is common for original cost estimates to be exceeded, due to unforeseen technical difficulties or other contingencies being encountered. The construction phase typically lasts for two to three years, although project delays are sometimes experienced.

The operation phase involves commercial exploitation of the mineral deposit(s), and typically runs for 50 years or more. Bulk mines involve the excavation of huge quantities of material, relatively limited on-site processing (e.g., crushing, screening and/or washing) of ore, and the conveying of saleable ore from the mine site to a port for onward shipping to international markets. In the initial operating period of a bulk mine, it might produce in the order of 20-30 million tonnes per annum of saleable ore. Later in the operating phase, output of the mine 
and the capacity of its associated infrastructure may be increased to meet additional market demand or improve the operation's competitiveness by lowering unit costs.

A mine's position on the global 'cost curve' determines its ability to withstand inevitable downturns in the price of the relevant commodity, which is outside the control of the mining firm. This is a key consideration for capital providers when evaluating the 'bankability' of a proposed project and, accordingly, lowest cost bulk mining projects tend to be developed in priority to higher cost projects. The cost, efficiency and reliability of a remote mine's pit-toport logistics solution is critically important in determining its relative position on the cost curve. The logistics solution for a typical bulk mining operation will comprise a heavy freight railway connected to a seaport capable of handling deep draught, 'Capesize' vessels. The cost of logistics facilities depends on a number of factors, including the distance from pit to port and the nature of the terrain covered, but is frequently greater than the cost of building the mine and its related processing facilities.

Various models are employed globally for the ownership, financing and operation of logistics infrastructure required by bulk mining operations. In a vertically integrated mining operation, the mine and its associated infrastructure are under common ownership and/or control. This model is generally employed when the mining firm determines that suitable logistics infrastructure is not available, and the host government is unable or unwilling to provide and/or operate it on acceptable terms. These circumstances frequently arise when a mineral deposit is found in a remote, undeveloped region of a developing country that lacks the financial and/or technical capacity to deliver or operate a major infrastructure project.

Bulk mining operations can also utilise public infrastructure, which is owned and operated by the state and/or a state-owned entity. This model can be attractive to mining firms when the host government has the capacity/credibility to fund and manage delivery of the infrastructure project, to pay compensation in the case of infrastructure project delays, to ensure reliable infrastructure operation, and to guarantee competitive and stable access tariffs.

The independent private infrastructure model involves the operation and, in some cases, ownership of mining infrastructure by a private firm that is independent of the mine and/or other users, and is generally in the business of operating numerous infrastructure facilities. This model often arises from the privatisation of public infrastructure facilities through an initial public offering or sale of an entity created to hold public infrastructure assets or a longterm right to operate and manage them. It also occasionally arises in the context of a 
greenfield mining project where the mining firm and/or host government decide that responsibility for the infrastructure facilities, including their funding, construction and/or operation, will be assigned to a third party.

Railway and port facilities constructed to support a bulk mining operation will generally have a throughput capacity that exceeds the initial planned output of the mine. This occurs either because the infrastructure cannot be designed with a lower capacity, or the mining firm elects to overbuild the infrastructure to accommodate increased throughput in the future. The capacity of a fully utilised railway or port can normally be increased through further capital investment. Due to the inherent physical characteristics of such facilities, the marginal cost (per unit of throughput) of adding capacity is, at least initially, quite low. Further capacity increases will eventually require a more substantial, 'step-change' investment. Invariably, the cost of expanding the capacity of existing infrastructure (even if a step-change is needed) is significantly lower than the cost of constructing new infrastructure having equivalent capacity.

Mining firms carefully allocate capital for high-risk exploration/development of mineral 'targets,' with each target competing with others within the firm's project portfolio. In the case of bulk mineral targets, early consideration will be given to potential logistics solutions. Where infrastructure is unavailable, mining firms will favour targets that are located in close proximity to coastal sites suited to a seaport development. This is explained by the fact that, as general rule, only large, 'world class' deposits (in terms of their size, grade and other characteristics) can support the huge cost of constructing extensive new railway and port facilities, and the likelihood of identifying such deposits is very low.

If logistics infrastructure already exists, the mining firm will seek answers to basic, but important questions: Is the infrastructure of a sufficient standard to support efficient mining operations and, if not, what is the likely cost of upgrading it? Does the infrastructure have sufficient unutilised capacity to support a new mine and, if not, is it possible to expand the capacity, and what would this cost? Who is responsible for granting rights of access to, and approving, funding and constructing any required upgrade or expansion of, the infrastructure, and is there a material risk that any required grants or approvals may be refused or delayed? What commercial and other terms would apply to rights of access to the infrastructure? Unless satisfactory answers to these questions can be obtained, the mining firm, when making its investment decisions, will heavily discount the potential benefits of existing infrastructure. 
There is, therefore, a strong link between a mining firm's decision to invest in mineral exploration and development, on the one hand, and what might be termed 'infrastructure risk,' on the other. All other things being equal, the higher the infrastructure risk associated with a particular target, the less willing a mining firm will be to make substantial investment in its exploration and development; and the converse also holds. For example, Glencore has described the infrastructure risk facing its coal business in Australia as follows: 'Having the ability to predict infrastructure availability and costs is essential in making appropriate investment decisions. Uncertainty of infrastructure costs or availability over the expected payback period of the investment diminishes the expected returns and lessens the ability for these returns to be forecast. Uncertainty undermines, if not destroys investment' (Glencore, 2014).

The mechanisms for third parties to gain access to mining logistics infrastructure vary by jurisdiction, but can be usefully grouped into the following categories: private negotiation, access undertaking and formal regulation. Under the private negotiation approach, a mining firm or other third party can gain access to existing mining infrastructure only if it is able to reach a negotiated access agreement with the infrastructure owner. The owner generally has no (or only a limited) obligation to negotiate, is unrestricted (or relatively free) in the negotiating positions it can take, and may withdraw from negotiations at any time. The access undertaking approach involves the infrastructure owner/operator making a contractual commitment to the host government concerning third-party access, which is often included within a mining concession agreement. Formal regulation involves a designated regulatory body or agency directly overseeing and resolving access-related issues and disputes. The approach can range from passive access regulation, where the regulator becomes involved only when needed to resolve disputes, to active access regulation, where the regulator is regularly involved in reviewing and approving access decisions, setting access tariffs and deciding other related matters.

\section{The Case for Open Access to Mining Infrastructure}

Newly-constructed railway, port and other critical infrastructure facilities are generally nonrivalrous services: until their capacity approaches full utilisation, the marginal cost of providing access to new users is extremely low. Such infrastructure also exhibits significant scale economies: it is more efficient to expand the capacity of existing facilities than to construct new, duplicate facilities. Furthermore, critical infrastructure often constitutes a natural monopoly: significant up-front fixed costs of construction (which are 'sunk' investments) combined with low marginal operating costs enable an owner/operator to deter 
potential market entrants from investing in competing services by, for example, engaging in short term predatory pricing behaviour. Moreover, even if competition between infrastructure facilities is achievable it may nevertheless be sub-optimal from a societal perspective insofar as it implies adverse environmental/social impacts or the inefficient allocation of capital to create excess/unneeded infrastructure capacity. Due to the foregoing characteristics, it is generally accepted that critical rail and port facilities require public ownership or, alternatively, public regulation to deter monopolistic pricing or other predatory behaviour and to ensure efficient levels of investment.

Critical rail and port infrastructure constructed to support a new bulk-mining project almost always creates potential opportunities for additional users. Until such infrastructure is actually in place, however, it can be difficult to identify these users because the normal process of trial and error by which opportunities are established cannot get fully underway. An important class of such opportunities is often the exploitation of other bulk mineral deposits by competing mining firms. The terms on which completed rail and port infrastructure can be used by third parties will largely determine whether and to what extent other mining firms elect to invest in the exploration activity necessary to discover and develop other deposits. If a mining firm holds unregulated private rights over its infrastructure, it retains the power of economic hold-up over competing mining firms. If a competing firm were to incur fixed exploration and development costs and successfully define a mineral deposit, the infrastructure owner could set terms of access that would extract from its competitor all rents associated with the deposit together with the entire value of any sunk costs. Since competing mining firms are aware of this power, a negotiation as to the terms of railway and port usage might be expected prior to any investment in exploration and development. However, even at this earlier stage, the unregulated infrastructure owner is in a position to extract from its competitor the entire expected rents from its proposed investment. As this, too, is known by all mining firms, they will simply avoid investing in exploration and development in the absence of regulation.

A mining firm holding unregulated private rights over critical rail and port infrastructure can also capture resource rents that would normally accrue to the state. In sub-Saharan Africa, for example, it is common for host governments to capture resource rents by auctioning mineral rights sequentially as a region gradually opens up to mining activity and the value of its mineral rights increases. If a first mover holds unregulated private rights over critical infrastructure in the region, potential bidders for these mineral rights cannot possibly know what to bid in the absence of a prior agreement with the first mover on access terms. However, in any such prior 
access negotiations the infrastructure owner can, through pricing of access rights, effectively pre-empt the state's share of the region's resource rents. And if the infrastructure owner wishes to secure for itself those regional mineral rights, it can simply refuse to negotiate with third parties and establish itself as the only credible bidder. In such a scenario, the infrastructure owner would have no incentive to pay more than a token amount for the explicit regional mineral rights, as it already owns the implicit rights over them.

Given the inherent uncertainty surrounding the existence of mineral deposits and the sequential nature of regional mineral discoveries, the value of rents associated with a region's mineral endowment is a classic instance of uncertainty as distinct to risk: no meaningful number can be placed on it. If a first-mover mining firm is allowed to hold unregulated private rights over critical rail and port infrastructure, it will (as explained above) acquire not only the explicit value of its initial mineral rights but also the implicit value of all yet-to-be-discovered mineral deposits in the same region. The value of such implicit rights is so uncertain that the first mover will be unwilling to bid up the price paid for its explicit rights. In this case, it is far better to leave the uncertain, but potentially massive, value of the implicit rights with society than allow a first mover to acquire them for no consideration.

For all these reasons, the public interest is overwhelmingly in favour of preserving future competition for mineral rights: only competition can ensure that the state, rather than an owner of critical infrastructure, captures the rents from future mineral exploitation. To maintain competition during the intrinsically sequential exploration and development process, a host government should therefore, in almost all cases, impose appropriate open access regulations on the infrastructure owner.

Open access regulation also has an important role to play in enabling mining-related infrastructure to serve as a catalyst for broad-based economic growth, particularly in subSaharan Africa (IFC, 2013; Collier, 2011). In 2009, this was recognised by the heads of state of African nations when, acting through the African Union, they adopted the 'African Mining Vision' (AMV), an initiative that seeks to put the continent's long term, broad development objectives at the heart of policymaking concerned with mineral extraction. The AMV's foundation report (African Mining Vision, 2009) called for, among other things, 'a knowledgedriven African mining sector that catalyses [and] contributes to the broad-based growth \& development of, and is fully integrated into, a single African market through [...] [s]ide-stream linkages into infrastructure (power, logistics, communications, water)'. The AMV initiative has subsequently drawn attention to the potential benefits of 'extending economic infrastructure', particularly power and transport, which the African Union notes is critical in 
mineral development (African Mining Vision Bulletin 2). The African Union urges Africa's policymakers 'to maximize the beneficial spill over effects of infrastructure triggered by mining by planning around resource corridors' and by encouraging its 'collateral or integral use by other economic sectors' including, for example, 'to promote rural development'. To achieve this, the African Union reminds policymakers that 'mineral transport infrastructure needs to allow third-party access at non-discriminatory tariffs'. Since 2009, success in achieving broad-based development around resource corridors, particularly those requiring cross-border coordination, has been limited (CMSI, 2012).

\section{$4 \quad$ Evaluating the Case Against Open Access to Mining Infrastructure}

Access to rail and port infrastructure has for many years provoked heated debate within the mining industry, with owners of integrated mining operations routinely defending their rights of ownership and access-seekers insisting on the need for open access regulation. In Australia, the regulation of access to mining infrastructure has received considerable attention from policymakers at the national and state-level during the last 20 years or so (see Appendix 1).

In early 2014, the Australian government asked an expert panel led by Professor lan Harper to conduct a 'root and branch' review of the country's national competition laws and policies. This included Australia's National Access Regime, which regulates (at the national level) access to 'bottleneck' infrastructure that is formally 'declared' by the government. In public submissions to the Harper Panel, several major mining firms and other commentators made public their views on access regulation of rail and port infrastructure in Australia used principally for transporting iron ore and coal. We set out below, and evaluate, the main arguments made by Rio Tinto, BHP Billiton and Ergas and Fels against open access regulation, drawing, where appropriate, upon arguments made by Anglo American and Glencore in support of such regulation. We also address commentary on access to mining infrastructure included in a report published in 2013 by the International Finance Corporation (which was unconnected to the Australian process).

Some opponents of open access regulation of mining infrastructure claim that it is unnecessary in light of market pressures. BHP Billiton and Rio Tinto, for example, argue that private infrastructure owners have a strong incentive to maximise its value and will, therefore, enter into access arrangements with third parties whenever the benefits of such arrangements outweigh the costs to them (Rio Tinto, 2014; BHP Billiton (Response), 2014). In the absence of a clear market failure preventing owners and access-seekers from reaching mutually acceptable outcomes, open access regulation is said to be an unnecessary and unjustified restriction on the free exercise of private property rights. According to BHP 
Billiton, situations such as that which has arisen in the Pilbara region of Western Australia where access-seekers have for decades sought with only limited success to secure access to railway and port infrastructure (see Appendix 1), will only arise when the costs to infrastructure owners of granting third-party access vastly exceed the potential benefits to such owners.

These market-based arguments against regulation suffer from several flaws. First, they ignore the potential for the holder of unregulated private rights over infrastructure to extract a disproportionate share (or even all) of the value of the access-seeker's mineral rights in any access negotiations (see also Glencore, 2014). In such a situation, the infrastructure owner has both the economic incentive and the power to extract maximum gains (see also Anglo, 2014). Secondly, the likelihood of such one-sided access negotiations has a chilling effect on investment in mineral exploration and development (Glencore, 2014; Anglo, 2014). In effect, the imagined negotiation rarely occurs because potential projects that might benefit from access to infrastructure fail to materialise due to lack of investment. Whilst it is true that significant investment in exploration/development has historically occurred in the Pilbara, this was likely induced by the National Access Regime, which mining firms assumed (wrongly, as it turned out) would enable them to gain access to existing infrastructure on reasonable terms. Thirdly, such arguments ignore the wider public interest in ensuring open access to infrastructure. Whether or not the costs to an infrastructure owner of granting access to a third party exceed the benefits to such owner, open access regulation nevertheless promotes the wider public interest. The granting of access to a mining firm or other access-seeker may, for example, increase the value of the state's share of resource rents, promote broad-based economic development, increase domestic participation in the mining sector, and/or diversify the host county's foreign investor base.

Opponents of open access regulation argue that the costs imposed by such regulations create economic inefficiencies and market distortions. Ergas and Fels, for example, advised the Harper Panel that the declaration of vertically integrated commercial facilities (e.g., the integrated iron ore mines in the Pilbara) for open access under Australia's National Access Regime 'would give rise to a range of economic costs that may be very large' (Ergas and Fels, 2014). BHP Billiton endorsed this view. Rio Tinto, for its part, warned the Harper Panel that granting infrastructure access in the 'wrong circumstances' could cause potentially 'enormous' costs to be incurred by the firms involved, and Australia as a whole (Rio Tinto, 2014). The costs in question are said to relate to, among other things, third party access applications, access disputes, incremental capital investment, disruption of vertically 
integrated processes, and delays to infrastructure expansions and improvements (BHP Billiton (Response), 2014). The adverse consequences of such costs are said to include misallocation of resources, pricing inefficiencies, infrastructure capacity losses, lower resource rents, reduced mining competitiveness, and dynamic investment inefficiencies.

Many of the unquantified costs and inefficiencies identified by Ergas and Fels, BHP Billiton and Rio Tinto can, in our view, be eliminated or reduced significantly through well-designed open access regulation. Whilst a detailed examination of Australia's National Access Regime is beyond the scope of this article, the flawed design of that particular regime has given rise to a wide range of technical and legal issues and uncertainties. These have led, inevitably, to many costly and time-consuming disputes between infrastructure owners and access-seekers that, in our view, were largely avoidable. We do accept, however, that even well framed open access regulation will involve a degree of unavoidable costs. The relevant question is whether such costs are likely to be outweighed by the benefits of regulation. As we have shown, these benefits can potentially include greater investment in mineral exploration and development and higher resource rents for the state. It seems likely that, in almost all cases, such benefits will vastly outweigh the expected costs (see also Glencore, 2014). Moreover, if the unavoidable costs of access regulation are being unfairly borne by infrastructure owners, it is possible to reimburse them for these through higher access tariffs, payments by the host government or other appropriate mechanisms.

Another line of argument against open access regulation holds that such regulation acts as a disincentive for investment. BHP Billiton, Rio Tinto and even the Australian Productivity Commission (Productivity Commission, 2013) have expressed concern that Australia's National Access Regime creates disincentives for mining firms to invest in greenfield mining projects and the expansion of existing operations. Such disincentives arise, they say, due to uncertainties as to whether and when third parties might seek access, whether an infrastructure owner will be able to use available infrastructure capacity for its own mining operations, the commercial terms of access, and the priority arrangements (if any) that will apply in a shared-use environment. BHP Billiton claims that 'the existence of the [Australian National Access Regime] increases uncertainty about whether and on what terms access must be provided to third parties [and that] this is a key disincentive to private investment in nationally significant infrastructure, and encourages investors to reduce the scale of their investments'. Specifically, it claims that the 'prospect that access obligations will be imposed on [...] infrastructure undermines an owner's ability to answer critical questions, such as: What do I get for my money? [...] Must I allow others to use the infrastructure? [...] How can I use 
my infrastructure? [...] Who, if anyone, will have priority to use the infrastructure?'. Moreover, where access regulations can oblige an infrastructure owner to incur risks associated with an infrastructure expansion undertaken for the benefit of an access-seeker, the possibility of this scenario is said to serve as a further disincentive (BHP Billiton (Submission), 2014).

Concerns that regulation of infrastructure access creates a disincentive for a first mover to invest can, once again, largely be addressed through appropriate regulatory design. If the open access regulation entitles third parties to gain access to infrastructure on terms that do not fully and fairly reflect an appropriate proportion of the owner's operating and capital costs, this would indeed create a disincentive for investment. A first mover would, in effect, be asked to assume the additional risk that it might be required, in the future, to subsidise one or more eventual access seekers. Open access regulation should, in our view, require access tariffs to be fully cost-reflective and, accordingly, create neither an incentive nor a disincentive for infrastructure investment.

In a related but separate argument, the International Finance Corporation has suggested that imposing open access obligations on a first mover mining firm could adversely affect the 'bankability' of an initial mining project (IFC, 2013). The IFC points to the dearth of multiuser/multi-client mining-related infrastructure projects globally and, in particular, in subSaharan Africa, which suggests there are limited options with respect to commercial structures that will result in successful project financing and execution'. The IFC argues that commercial lenders' risk appetite and focus on cash flows mean that 'the higher the complexity of the shared-use structure, the less bankable it will be'. In the IFC's view, '[f]inancial viability is even more unlikely if other users or clients are not known' at the time of financing the initial mining project. The IFC suggests, therefore, that any access regime should 'reflect the business and financial needs of the project's stakeholders at the time of project conception while acknowledging that changes in future business environment might require modifying the selected initial operating regime'. This 'pragmatic approach' could, in the IFC's view, be translated into the first mover's mining concession in a way that 'leaves some room for future renegotiations on a few key issues (i.e., tariff structure, transport capacity allocation, etc.) without diminishing project bankability'.

Whilst the IFC is correct to focus on the considerable challenge of raising financing for large mining projects in sub-Saharan Africa, imposing appropriate open access regulation on mining infrastructure should not, in our view, render such projects 'unbankable.' It will, of course, be important to ensure that any such regulation protects a first mover's access to and use of critical infrastructure and the operational efficiency of its mining project, in order to maintain 
the cash flows needed to service the project's debt. By extension, any agency or other body charged with enforcing such regulation will need to be robust, both in terms of its expertise and its independence from political and/or other extraneous factors. In developing countries, this may in practice imply 'external' regulatory oversight, at least for the term of any project loan. The first mover's contractual commitment to use and/or pay for the infrastructure will often be critical to securing project financing and, in such cases, project lenders will require assurance that third party access rights will not diminish this commitment. Whilst such a requirement may raise an issue of fairness as between the first mover and other users of the infrastructure, there is no reason such an arrangement could not be put in place. Moreover, any unfairness can be addressed by requiring subsequent users to provide appropriate compensation to the first mover for its commitment. Certainly, open access regulation can be complex, but project financing also involves elaborate commercial and legal structures with which sophisticated commercial lenders routinely become comfortable. In any event, we consider that any disadvantages associated with the complexity of open access regulation will generally be outweighed by the clear benefits for project lenders arising from the shared-use of mining infrastructure. In particular, the introduction of third parties willing and able to pay fully cost reflective tariffs for access to infrastructure will reduce the project's average unit costs, thereby increasing project cash flows available for debt service. Moreover, such third parties provide a degree of risk diversification to project lenders who would otherwise be entirely reliant on the cash flows from a single mining project. Finally, if the host government and local communities regard shared-use of the project's infrastructure as promoting greater resource rents and/or broad-based economic development, the lenders' exposure to political risks should be mitigated.

We are also concerned with the suggestion that host governments should defer reaching agreement with a first mover on the detailed rules for access to mining infrastructure and address these in a later renegotiation. In the absence of a clear and enforceable process for reaching future agreement on definitive access rules, experience in Australia suggests that first mover mining firms will strongly resist any meaningful renegotiation on this issue. Whilst a host government could seek to impose open access through legislation at a later stage, this might involve breaching contractual commitments to the first mover and/or its project lenders and, in any event, would likely be seen in a negative light by the global investment community (including other mining firms). All of this argues, in our view, for host governments grasping the nettle early and working with first movers to agree and/or impose comprehensive and workable open access regulation from the outset. 
Opponents of open access regulation have also claimed that such regulation is contrary to the national interest of commodity-exporting nations, including Australia. Ergas and Fels say access regulation is inappropriate in the case of 'vertically integrated infrastructure facilities used to export commodities whose prices are determined in competitive global markets'. They focus solely on the potential for competition benefits in downstream markets, arguing that '[d]eclaration [for open access] of vertically integrated facilities used to export commodities whose prices are determined in competitive global markets would not affect the prices of these commodities. Declaration would therefore not lead to competition benefits' (Ergas and Fels, 2014). They pay no attention to whether declaration of mining infrastructure for open access would lead to more entrants and greater competition in upstream markets (e.g., for the purchase/development of mineral rights) and/or midstream markets (e.g., for the provision of logistics services). BHP Billiton makes a similar argument in relation to 'privately developed single-user export infrastructure used in competitive global export markets' (BHP Billiton (Submission), 2014). It argues that regulating access to its Pilbara infrastructure 'is unnecessary [because] access regulation cannot promote competition in an end market that is already competitive, and the discipline of end market competition strongly incentivises the infrastructure owner to use its resources, including its infrastructure, as efficiently as possible'. It claims that 'requiring third party access [...] in this scenario will not promote competition in any significant market - instead, the downstream commodity market is already competitive'.

It appears that, at the core of this argument, is the notion that a bulk mineral-exporting country can best maximise its resource rents by encouraging the formation of a small number of large, highly efficient integrated bulk mining operators. By enabling such operators to maximise total output (e.g., by eliminating inefficiencies that might arise in a shared infrastructure network) and, consequently, minimise unit costs of production, the state will (it is suggested) receive greater resource rents in the form of volume-related royalties and profit taxes than it would if ownership of bulk mining was fragmented. It is inferred that access regulation tends to encourage ownership fragmentation and is, therefore, contrary to the public interest.

We take issue with both aspects. First, it is not in the public interest for one or a few owners of infrastructure to control the pace of development in a mineral region. Today, the Pilbara boasts highly efficient, large-scale mining operations that have become important 'profit engines' for Rio Tinto and BHP Billiton. It has, however, taken almost half a century to reach this point. Mining firms have varying levels of finite financial capacity, differing attitudes to 
risk, and distinct tolerances for exposure to 'high-risk' countries. Accordingly, an individual mining firm will be unable and/or unwilling to pursue all regional mineral targets at any given time. Thus, the public interest requires active competition for mineral rights to maximise the present value of the state's share of resource rents.

Secondly, conferring unregulated private rights over critical infrastructure is not necessary to achieve ownership consolidation (if this is, indeed, in the public interest). Open access regulation does not preclude an infrastructure owner and access seeker agreeing a transaction for the purchase of mineral rights by the infrastructure owner. Critically, it is the access-seeker's option to seek access to infrastructure on fair and reasonable terms that enables it to negotiate a fair sale price for its mineral rights. Indeed, this is precisely what happened in 2000 when Rio Tinto acquired North Limited for US\$2.8 billion following North's partially successful efforts to 'declare' Rio Tinto's Pilbara railway network under the National Access Regime. Providing mining firms with the ability to realise full and fair value for their mineral rights either through their exploitation or sale will, as we have shown, support greater investment in exploration and development activity. Such investment will, in most cases, result in more rapid achievement of the high production volumes and operating margins necessary to maximise the state's resource rents.

Finally, when governments seek to impose open access regulation on owners of vertically integrated mining operations after they have made their investments, arguments based on fairness and investor confidence are often advanced. Such ex post facto regulation, it is said, unfairly undermines key assumptions upon which major investments were made, including who will be entitled to use the infrastructure and what access tariffs will be paid by third parties. Ex post facto access regulation is also said to result in the effective transfer of value from infrastructure owners to access seekers and is therefore sometimes characterised as an act of partial expropriation without compensation. Imposing access regulation in this manner is said to undermine investor confidence, and to render infrastructure owners and other potential first movers less willing to invest.

The public interest in ensuring open access to critical infrastructure on fair and reasonable terms should, and generally does, take priority over private rights of ownership. In 1912, the U.S. Supreme Court, in Terminal Railway, used the (then relatively new) Sherman Act to require owners of a critical railway terminal to grant access to third parties (United States $v$. Terminal Railroad Association, 224 U.S. 383 (1912)). This decision gave rise to the so-called 'essential facilities doctrine,' which has over the last century evolved globally into a vast array of access-related regulations and court decisions that apply to railways, pipelines, 
communication networks, power transmission grids and similar facilities. After more than 100 years of regulatory and judicial intervention, owners of essential facilities such as railways and ports used in bulk mining operations can, we would argue, generally be taken to have assumed the risk of such intervention. Nevertheless, we consider that host governments should, whenever possible, proactively develop and impose comprehensive open access regulation at or prior to the time that private investment in mining infrastructure is initially made.

\section{$5 \quad$ Practical Considerations for Host Governments}

On the basis of the arguments set out in sections 3 and 4 above, we believe that host governments are, in almost all cases, well advised to develop and implement open-access regulation governing the use of mining infrastructure. This is however no light task and, to protect their national interests, governments need to consider a range of important matters, including: their regulatory objectives, the appropriate regulatory framework and their own internal capacity.

When seeking to regulate access to mining infrastructure, a host government should endeavour clearly to identify its policy objectives. These will depend upon a range of factors that vary from country to country, but will often include: geography and location, the existence of any known mineral deposits, the country's mineral development potential, the availability of existing infrastructure, the ownership and other arrangements in place for any existing infrastructure, the potential for development of non-mining industries (e.g., agribusiness), the state of the country's public finances, and so on. Often, open access regulation will need to be tailored to specific opportunities and challenges. For example, such regulation may need to address concerns that owners of existing integrated mining operations are abusing their position by blocking access and/or charging excessively for access rights. Alternatively, regulation may need to address the need for expansion of mining infrastructure to support the development of new mines. In other cases, regulation may need to encourage coordination among the sponsors of several small, marginal mining projects to secure private financing of a common infrastructure solution.

A workable open access framework should provide a clear description of the infrastructure that is available for shared use. It should also include clear and realistic timeframes for each step in the access application process, together with a practical and reliable procedure for resolving disputes, including those arising during the period of shared use. The framework should provide access seekers with ready access to information on technical, operational and other aspects of the infrastructure, including current capacity utilisation and options for future expansions. The framework should also specify the conditions that must be satisfied 
before an access-seeker can make an application, including any financial, technical and operational qualifications or project milestones. The basis for determining access tariffs should be clearly specified, along with other key access terms such as the duration of access rights, the conditions for renewal/extension of such rights, and the nature of an accessseekers' commitment (e.g., 'take-or-pay' vs. 'best efforts' commitment). Clear operating procedures for the shared infrastructure, or a credible mechanism for determining these, should also be provided. These may, for example, include provision for the first mover to have operational priority in certain circumstances. Finally, if an infrastructure owner can be required to undertake or permit expansion of its facilities, the procedure to be followed and conditions to be satisfied should be detailed.

If the host government is in a position to require distinct ownership/operation of mining activities, on the one hand, and mining infrastructure, on the other, it is often well advised to do so. When a competent, independent operator is managing infrastructure that has been 'unbundled' from its mining 'client,' this reduces the potential for conflicts of interest when access applications arise. Although regulation of an independent infrastructure operator is still necessary to prevent monopolistic pricing behaviour, a 'light touch' approach can often be employed. Globally, there are some good examples of effective, workable open access regulation being applied to bulk mining infrastructure. In Appendix 2, we describe the efficient railway network in the coal basin of Queensland, Australia, which is operated by Aurizon (a regulated private company) and serves more than 50 coal mines as well as freight, container and passenger traffic using several competing 'above-rail' operators.

Experience in the Pilbara with regulating access to mining infrastructure illustrates the importance of designing and enforcing a robust, effective open access framework. Railway and port infrastructure clearly represents a critical 'competitive battleground' for mining firms, with owners of integrated mines and access seekers willing to exploit any regulatory gaps or uncertainties for their own commercial advantage. Strategies and tactics employed by major mining firms in the Pilbara and elsewhere around the world to defeat the intent of open access regulation have included: launching aggressive legal challenges designed to defeat or at least delay access applications made by smaller, poorly-capitalised firms; adopting engineering solutions and design features that render sharing with third parties challenging or impossible; entering into pre-emptive access arrangements with small or marginal users; and deploying rolling stock or other assets inefficiently in order to enable a first mover to 'consume' available infrastructure capacity until it is later required. To counter the significant financial and other resources available to many mining firms, host governments need to 
develop internal capacity and/or retain expert external support covering several specialist areas including economic regulation, mineral economics, engineering and design, operations management, project finance and dispute resolution.

Governments of developing countries, including in sub-Saharan Africa, should be cautious about simply replicating open access frameworks used in developed countries (e.g., Australia) when devising their own shared mining infrastructure solutions. There can be important contextual differences that require different and, in some cases, bespoke legal and regulatory approaches. For example, the use of a domestic regulatory agency to make determinations and resolve disputes under a shared infrastructure framework, which is common in countries with an established regulatory 'track-record,' may be not be practicable in certain developing countries. Where a first mover mining firm (or other key stakeholder) would have legitimate concerns that a domestic regulator lacks the expertise necessary to make reliable decisions on matters of a technical nature or the requisite independence from political or other extraneous influences, alternatives to domestic regulation should be considered (e.g., the use of international centres of expertise, contractual mechanisms, etc.). Another contextual difference arises from Africa's relatively high degree of political fragmentation (54 countries, 16 of which are landlocked). While there are many 'single country' bulk mining operations and/or projects in sub-Saharan Africa that are candidates for shared infrastructure solutions ${ }^{1}$, an additional group of projects will require a cross-border logistics solution. Such 'crossborder projects' are subject to a range of unique risks and issues that do not normally arise in purely 'domestic' projects. These often include a lack of support and/or cooperation from the relevant 'transit' country, the government of which often sees limited direct benefits from the project and/or may sense an opportunity to extract onerous 'transit fees'. The prospect of promoting broad-based economic development in the transit country through sharing of infrastructure can serve as an effective inducement for transit country cooperation. In these situations, the governments involved must focus carefully on achieving a mutually-acceptable, reliable and efficient transnational regulatory structure for the infrastructure corridor. A further contextual difference can arise in developing countries with a poor track-record of

\footnotetext{
${ }^{1}$ Examples include: Askaf (iron ore - Mauritania); Belinga (iron ore - Gabon); Boffa (bauxite - Guinea); COMILOG (manganese - Gabon); Faleme (iron ore - Senegal); Kango (iron ore - Gabon); Nimba Project (iron ore - Guinea); Marampa (iron ore - Sierra Leone); Mayoko (iron ore - Republic of Congo); Nkout (iron ore - Cameroon); Putu (iron ore Liberia); Simandou North (iron ore - Guinea); Simandou South (iron ore - Guinea); and Tonkolili (iron ore - Sierra Leone).
} 
protecting foreign investors and/or respecting investment agreements. In this scenario, mining firms will be concerned to ensure that critical logistics infrastructure does not fall under the operational control of the state, through nationalisation or otherwise. The significance of this risk (real or perceived) can increase if a host government insists on structural separation of a proposed mine and its associated infrastructure as part of its preferred shared-use infrastructure framework. To address legitimate investor concerns, it may be appropriate to incorporate enhanced commercial and/or legal protections within the agreed shared infrastructure framework, including so-called 'step-in rights' or similar mechanisms.

In view of the range of technical and commercial issues that open access regulation raises and the considerable pressures that sometimes arise during negotiations with first mover mining firms, many governments in sub-Saharan Africa (in particular) might legitimately question their internal capacity to develop and enforce open access regulation in a manner consistent with their national interest. Fortunately, a number of useful resources are now available for government officials who are in the early stages of considering such regulation (see, for example: CCSI, 2014 and IFC, 2013). Moreover, the Milken Institute has recently announced a major initiative that seeks to establish detailed, written 'norms' for the sharing of mining infrastructure, which could be incorporated (perhaps with some tailoring, to address local circumstances) by host governments into their mining concession agreements, tender documentation and so forth. Milken has proposed a process that will include extensive public consultations involving any mining firms, host governments, development agencies, nongovernmental organisations, regulatory bodies and other stakeholders that support the emergence of globally-accepted 'best practices' in this area.

\section{Conclusion}

Rail and port logistics infrastructure is critically important to bulk mining operations. The large fixed costs and potential inefficiencies involved in duplicating such infrastructure confer a significant competitive advantage on its owner in the absence of effective access regulation. In particular, where a first-mover develops an 'integrated' project incorporating a mine and associated infrastructure, a failure to impose access regulation discourages third-party investment in mineral exploration and development in the region serviced by the infrastructure, due to the risk of hold up by the first mover. An unregulated first mover can further use its infrastructure advantage to capture the state's share of resource rents from the mineral endowment of the region. Open access regulation of mining infrastructure can address these concerns, encouraging upstream investment by reducing infrastructure risk and 
increasing the state's share of resource rents. Such regulation also benefits host countries by enabling broad-based economic development through the shared-use of mining infrastructure with other sectors (e.g., agribusiness, freight transportation and passenger services). Accordingly, we consider that host country governments should proactively impose and then take steps to enforce effective open access regulation on mining infrastructure in almost all cases. The Pilbara experience with mining infrastructure access demonstrates that this area represents a critical competitive battleground within the industry, and that the interests of private sector combatants are not necessarily aligned with a host country's national interest. The approach taken in Queensland, Australia, however, shows that it is possible to regulate effectively for open access to mining infrastructure in a manner consistent with the national interest. However, host governments (particularly those in sub-Saharan Africa) should not underestimate the internal capacity and other challenges associated with effective policymaking and governance in this area.

\section{Appendix 1 Infrastructure Access in the Pilbara, Western Australia}

\section{Australia's 'National Access Regime'}

In the 1960s, predecessors of Rio Tinto and BHP Billiton took the decision to construct large mines and associated rail and port infrastructure to exploit large ore deposits in the remote, and then undeveloped Pilbara region of Western Australia. Over the last four decades, these mines have - through expansion and further investment - evolved into large, efficient and highly profitable operations. In the process, Western Australia has enjoyed one of the fastest growing mining sectors in the world. The Pilbara operations of Rio Tinto and BHP Billiton are among the lowest cost mines in the global iron ore industry, enabling them to remain profitable despite recent declines in iron ore prices. Rio Tinto and BHP Billiton's integrated Pilbara mines are governed by so-called State Agreements (i.e., mining concessions) entered into with the Government of Western Australia. These contain, among other things, limited and highly conditional undertakings regarding the granting of third-party access to their infrastructure.

In 1995, the government of the Commonwealth of Australia introduced a 'National Access Regime' (NAR) as part of wider national competition policy reforms. The stated purposes of the NAR were (1) to promote the economically efficient operation of, use of and investment in the infrastructure by which services are provided, thereby promoting effective competition 
in upstream and downstream markets; and (2) to provide a framework and guiding principles to encourage a consistent approach to access regulation in each industry. The NAR operates as an umbrella framework and, accordingly, does not apply to situations where a State-level, industry-specific or other qualifying access undertaking is in place. (Since the NAR's introduction, many such qualifying undertakings have been introduced governing access to a range of infrastructure facilities across the country.)

Upon application by a person seeking access to qualifying 'bottleneck' infrastructure in Australia, the NAR empowers government to 'declare' the infrastructure, subject to certain conditions being met. A declaration enables access-seekers to require the infrastructure owner to negotiate access terms. The NAR provides for resolution of access disputes by way of arbitration conducted by the Australian Competition and Consumer Commission (ACCC).

In the early 2000s, unprecedented growth in Chinese steel production led to surging demand for iron ore. Holders of mineral rights in the Pilbara, including Fortescue Metals Group and Hancock Prospecting, sought to develop new iron ore mines. An affiliate of Fortescue, TPI, succeeded in having part of BHP Billiton's Pilbara rail and port infrastructure declared under the NAR. BHP Billiton, with supportive intervention from Rio Tinto, challenged the legal validity of the government's declaration. This led to the well-known 'Pilbara railway case,' which dragged on, at great cost, for many years. The Australian courts finally determined, in 2013, that the Australian government had not met the conditions for declaring the infrastructure for open access. The court's decision hinged on its narrow interpretation of the NAR, which placed an onus on Fortescue and other access-seekers to establish that they could not viably construct their own infrastructure facilities (known as the 'private profitability test').

To date, the only Pilbara iron ore infrastructure to be successfully declared under the NAR is the 'Goldsworthy' line (a relatively minor section of BHP Billiton's railway) and no party has sought access to it.

\section{State-Level Access Regulation in Australia}

Despite its defeat in the Pilbara railway case, Fortescue, with support from the government of Western Australia, elected to construct its own rail and port infrastructure. It secured the funding required, and successfully constructed the fully integrated Cloudbreak mine. The Western Australian government required Fortescue to operate its infrastructure on an open access basis according to a State Agreement, existing State-level access regulations and a formal access undertaking entered into by TPI. Subsequently, Hancock Prospecting entered 
into similar access arrangements in Western Australia in connection with its Roy Hill integrated project, which is now nearing completion. The railway operations of BHP Billiton, Fortescue and Roy Hill all run parallel to one another and terminate at Port Hedland, where each company operates its own dedicated loading facilities.

In 2006, Fortescue entered into arrangements with junior miner BC Iron, under which Fortescue acquired a $25 \%$ joint venture interest in the junior's Nullagine project and granted rail and port access for the project on purportedly arm's length terms. This was one of the first examples of meaningful rail/port infrastructure sharing between mining firms in the Pilbara. It seemed that the Government of Western Australia was on track to achieve what the NAR had failed to do. However, in 2013, when another junior, Brockman Mining, sought access to Fortescue's infrastructure for its proposed Marillana project it faced strong resistance. Fortescue proposed 'floor and ceiling' prices for access (as contemplated under its access regime) that many industry observers regarded as aggressive. In September 2013, Western Australia's access regulator, the Economic Regulatory Authority (ERA), rejected Fortescue's proposed access pricing range, and imposed a materially lower 'ceiling' price. Fortescue then challenged the ERA's determination by way of judicial review, and succeeded in obtaining a court order requiring the ERA to reconsider its decision. Fortescue also commenced litigation to challenge the validity of Brockman's access application, arguing that Brockman had no clear intention or motive for seeking access and had neither the financial ability nor managerial expertise to develop its project. When announcing Fortescue's intention to appeal the Supreme Court of Western Australia's decision rejecting this challenge, chief executive Nev Power insisted that Fortescue is still 'a strong proponent of third-party access to infrastructure' but that 'it cannot be expected to subsidise third-party projects that are uneconomic'.

In June 2013, a frustrated Colin Barnett, the Premier of Western Australia, complained publicly that 'the biggest obstacle to timeliness and keeping costs down [in natural resource projects in Western Australia] is disputes and lack of agreement and a lack of sharing infrastructure in the mining and petroleum sectors' and that 'the companies need to look at themselves'.

\section{Appendix 2 Open Access Regulation in the Central Queensland Coal Network}

Aurizon is Australia's largest rail freight operator and a top 50 ASX company. Formed by privatisation in 2010, it operates the Central Queensland Coal Network (CQCN), which is one of the world's largest coal rail networks linking more than 50 mines with three major ports at Bowen, Gladstone and Mackay. An Aurizon subsidiary, Aurizon Network, holds a 99-year lease (which commenced in 2010) over the 'below rail' assets comprising the CQCN. Aurizon 
Network controls, manages, operates and maintains the CQCN'S fixed rail network, and is regulated by the Queensland Competition Authority (QCA). Aurizon's above-rail business, which is structurally separated from Aurizon Network, comprises freight, container and passenger services using an extensive fleet of rolling stock and competes with other third party rail freight companies operating on the CQCN.

Aurizon Network is required to enter into an Access Undertaking with the QCA, which addresses a range of matters including the negotiating framework for access seekers (information, timing and processes), pricing (tariffs, limits and differentiation), connections and network expansion, capacity management (transfers, resumption and relinquishment), reporting, revenue management (caps, pass-through and variations), operational separation and Aurizon Networks' non-discrimination obligations.

Aurizon Network generates revenue in the form of access charges, which are regulated by the QCA. The regulatory model employed is a conventional 'revenue cap.' Aurizon earns a set return on its 'regulatory asset base' (RAB) over the regulatory period up to the 'maximum allowable revenue' (MAB). The RAB is determined on a 'depreciated optimal replacement cost' (DORC) basis, and is adjusted annually with reference to inflation, asset depreciation, proposed capital expenditure and asset disposals. The MAB is determined by the QCA as the sum of (i) Aurizon Networks' permitted return on the RAB (using Aurizon's weighted average cost of capital) and (ii) the cost of operating the CQCN.

To facilitate third party access, Aurizon publishes a 'reference tariff' for certain specified routes, which serves as the basis for negotiation of actual access charges for new users. Aurizon Network must provide access to the CQCN to all accredited rail operations, which currently comprise Aurizon itself, Pacific National and BMA. Mining firms typically contract with these accredited operators to move their coal. In the event of a breakdown in access negotiations, the matter is resolved using a dispute resolution framework set out in Aurizon Network's Access Undertaking.

Mining firms are generally obliged to enter into long-term take-or-pay (TOP) contracts when securing rights of access to the CQCN for a new mine. With global coal prices now severely depressed and many coal mines in Queensland under financial pressure, these TOP commitments have come into greater focus recently. Some mining firms have complained that the fixed costs associated with their TOP contracts are unfairly forcing them to continue producing at a loss, which is contributing to downward pressure on global prices. Aurizon appears reluctant to consider renegotiation of the current arrangements. 
In the case of significant expansions to the CQCN, including the so-called 'GAPE' and 'WIRP' projects, Aurizon Network has negotiated additional economic returns from users to compensate it for the significant construction, financial and other risks assumed by it.

The CQCN is generally regarded as a good example of how large-scale, multi-user, multipurpose logistics infrastructure used by efficient bulk mining operations can be effectively structured and regulated. The model has, however, been the subject of periodic criticisms from mining firms (see, for example: Glencore, 2014).

first received February 2016

final revision accepted August 2016

\section{References}

African Mining Vision (2009)

(http://www.africaminingvision.org/amv_resources/AMV/Africa_Mining_Vision_Englis h.pdf).

African Mining Vision Bulletin 2

(http://www.africaminingvision.org/amv_resources/ISGbulletin2.pdf).

Anglo American Metallurgical Coal (Anglo) (2014) 'Submission to the Competition Policy

Review Panel'. (http://competitionpolicyreview.gov.au/issues-paper/submissions/).

BHP Billiton (2014) 'Submission to the Competition Policy Review'.

(http://competitionpolicyreview.gov.au/issues-paper/submissions/).

BHP Billiton (2014) 'Response to the Draft Report of the Competition Policy Review'.

(http://competitionpolicyreview.gov.au/draft-report/non-confidential-submissions/).

Collier, P. (2010) 'The plundered planet: How to reconcile prosperity with nature.' London: Allen Lane.

Collier P. (2011) 'Building an African Infrastructure, Finance and Development'. International Monetary Fund. (http://www.imf.org/external/pubs/ft/fandd/2011/12/collier.htm).

Columbia Center on Sustainable Investment (CCSI) (2014) 'A Framework to Approach Shared Use of Mining-Related Infrastructure'. (http://ccsi.columbia.edu/files/2014/05/AFramework-for-Shared-use_March-2014.pdf). 
Ergas H and Fels A. (2014) 'Submission to the Competition Policy Review'.

(http://competitionpolicyreview.gov.au/draft-report/non-confidential-submissions/).

Glencore Coal (Glencore) (2014) 'Submission to Competition Policy Review'.

(http://competitionpolicyreview.gov.au/draft-report/non-confidential-submissions/).

International Finance Corporation (IFC) (2013) 'Fostering the Development of Greenfield

Mining- Related Transport Infrastructure Through Project Financing'.

(http://www.ifc.org/wps/wcm/connect/c019bf004f4c6ebfbd99ff032730e94e/Mine+Inf ra+Report+Final+Copy.pdf?MOD=AJPERES).

Productivity Commission (2013) 'Inquiry Report No 66 (National Access Regime)'.

(http://parlinfo.aph.gov.au/parllnfo/search/display/display.w3p;query=ld\%3A\%22publi cations\%2Ftabledpapers\%2F71836\%22).

Rio Tinto Iron Ore (Rio Tinto) (2014) 'Submission on Part IIIA of the Competition and Consumer Act, 2014'. (http://competitionpolicyreview.gov.au/issuespaper/submissions/).

School of Mining Engineering and Centre for Sustainability in Mining and Industry (CSMI), University of the Witwatersrand (2012) 'Resource Corridors: Experiences, Economics and Engagement; A Typology of Sub-Saharan African Corridors'. (http://www.eisourcebook.org/cms/files/EISB\%20Resources\%20Corridors.pdf) 